Original Research Article

\title{
Comparison of metabolic effects of glimepride and sitagliptin with metformin in patients suffering from type 2 diabetes mellitus in a tertiary care hospital
}

\author{
Preeti Singh, Ruchi Choudhary*, V. K. Singh, Prithpal S. Matreja
}

\begin{abstract}
Department of Pharmacology, Teerthanker Mahaveer Medical College, Moradabad, Uttar Pradesh, India
\end{abstract}

Received: 06 June 2019

Revised: 10 June 2019

Accepted: 13 June 2019

\section{*Correspondence to: \\ Dr. Ruchi Choudhary, Email: Ruchi.upmanyu@ gmail.com}

Copyright: (C) the author(s), publisher and licensee Medip Academy. This is an openaccess article distributed under the terms of the Creative Commons Attribution NonCommercial License, which permits unrestricted noncommercial use, distribution, and reproduction in any medium, provided the original work is properly cited.

\begin{abstract}
Background: Diabetes mellitus (DM) is one of the major causes of mortality \& morbidity, and patient's with better control of glycaemic parameters have lesser chronic complications associated with it. Though monotherapy with metformin is first choice for T2DM but is effective in less than $50 \%$ of patient and they should be managed with two drug therapy. Both Glimepiride and Sitagliptin are effective with metformin but there has been no study done in this region hence, we planned to study comparison of effects of glimepiride and sitagliptin with metformin in patient of T2DM.

Methods: This prospective, open-label, randomized study was done in all patient diagnosed with T2DM, not adequately managed by metformin alone. The patient was divided into two group $\mathrm{G}$ (Glimepiride with Metformin) and Group S (Sitagliptin with Metformin) and had a follow up at 3 and 6 months. The biochemical parameters were assessed at 12 weeks and 24 weeks.

Results: The result of this study show that both glimepiride and sitagliptin with metformin significantly $(\mathrm{p}<0.05)$ lowered both the fasting blood sugar as well as postprandial blood glucose at 3 and 6 months. Glimepiride was more effective in lowering $(\mathrm{p}<0.05)$ the plasma glucose at 3 months but both the drugs had comparable result at 6 months. This study also showed that glycosylated haemoglobin was lowered in both groups at three and six months as compared to Day $0 \quad(\mathrm{p}<0.05)$, with glimepiride having better control of glycosylated haemoglobin at 3 months with both groups having comparable result at 6 months. Conclusions: To conclude, this study compared effects of sitagliptin and glimepiride on glycaemic parameters in patients of T2DM and found that both drugs had comparable results.
\end{abstract}

Keywords: Diabetes mellitus, Fasting blood sugar, Glycosylated haemoglobin, Post-prandial blood glucose

\section{INTRODUCTION}

Diabetes mellitus is a major cause of morbidity and mortality in developing countries like India with a rise in number of patients suffering from the disease with each passing day. ${ }^{1}$ The management of T2DM involves both life style modification as well as pharmacotherapy for control of plasma glucose levels to decrease long term complications associated with the disease. ${ }^{2}$ As per the recommendations of European Association for diabetes mellitus and American Diabetes Association (ADA) the initial recommendation for patients suffering from T2DM is monotherapy with biguanides (Metformin). ${ }^{1}$

Studies have found monotherapy alone to be insufficient, due to progressive worsening of the disease more than $50 \%$ 
of the patients are started on two drug therapy for long term control of plasma glucose levels. ${ }^{2}$ In Indian set-up drugs belonging to sulfonylurea group like glimepiride are most accepted second-line drugs to be combined with metformin. ${ }^{3,4}$

Glimepiride is most preferred and frequently used with metformin for control of blood glucose levels. ${ }^{5,6}$ The second drug added to metformin has most of the times been sulfonylureas, Glimepiride is approved by United States Food and Drug Administration both as monotherapy as well as in combination with either metformin or insulin in patients suffering from T2DM. ${ }^{7}$ Glimepiride has shown to have optimal insulin secretion, as well as extra pancreatic effects though frequent hypoglycaemia and weight gain hamper its long-term use. ${ }^{7-9}$ There is always a search for drugs with low risk for hypoglycaemia and are weight neutral effects and this has led to development of important and effective incretin-based therapy, Dipeptidyl Peptidase-4 (DPP-4) inhibitor as adjunctive drugs in T2DM in the past few years. ${ }^{10,11}$ Studies done on DPP-4 inhibitors like sitagliptin have shown that this drug is welltolerated, has a low risk of causing hypoglycaemia and do not affect the weight of the patients. ${ }^{10,11}$ Few studies have also suggested that DPP-4 inhibitors like sitagliptin also have cardiovascular protective effects, as it improved function of heart and coronary perfusion as well as decreased blood pressure with a favourable response on lipid parameters. ${ }^{10,12,13}$ There is paucity of data on any precise combination having better efficiency on lowering blood glucose levels as well as preventing long-term complications along with improving the quality of life of patients. ${ }^{14-16}$ The decision to start a particular combination therapy in any patient suffering from T2DM depends on many factors which include patient's satisfaction, economic status of the patient and any other patient's specific criteria. A thorough literature search revealed limited studies done for comparison of sitagliptin and glimepiride with metformin in this region, hence, the study was planned for comparison of glycaemic parameters on patients with type 2 diabetes mellitus on treatment with either glimepiride or sitagliptin with metformin.

\section{METHODS}

This prospective, randomized, parallel-group, open-label study was done on patients suffering from T2DM at a tertiary care hospital in North India for a duration of 2 years between December 2016 to November 2018. Approval for study was taken by IEC (Institutional Ethics Committee) and conducted as per Good Clinical Practice (GCP) Guidelines. All patients who gave a written informed consent were enrolled in the study. All patients suffering from T2DM as per ADA guidelines. ${ }^{[17]}$ were screened for participation in the study. All patients diagnosed with T2DM not well-regulated with metformin therapy were included in the study. Patient age more than 30 years were included in the study after obtaining written informed consent. All patients hypersensitive to the drug, not willing to comply with study guidelines, with associated medical or surgical co-morbidities were excluded from the study. Pregnancy and lactating females were also excluded from the study. Patients enrolled in the study underwent a thorough clinical examination and were randomly allocated using random number table into two groups. Patients in Group $\mathrm{G}$ received Glimepiride with Metformin, whereas patients in Group $S$ were on Sitagliptin with Metformin. Patients on Metformin monotherapy for a period of 3 weeks or more with uncontrolled glycaemic parameters and at a dose of $\geq 2$ grams day $^{-1}$ for a duration of 3 weeks and glycaemic control not achieved with Metformin monotherapy were treated either with glimepiride $(5 \mathrm{mg} /$ day) or Sitagliptin (100 mg/day).

\section{Group $G$}

The patient's in this group to receive therapy of metformin at a dose of $500 \mathrm{mg}$ three times a day along with glimepiride at dose of $5 \mathrm{mg}$ twice a day for a duration of six months.

\section{Group $S$}

The patients in this group to receive therapy of metformin at a dose of $500 \mathrm{mg}$ three times a day along with sitagliptin $100 \mathrm{mg}$ once a day for a period of 6 months.

\section{Diagnosis of Diabetes mellitus}

As per the guidelines of ADA fasting plasma glucose (FPG), 2hours postprandial plasma glucose (2-hour PG), and glycosylated haemoglobin are reliable and convenient test for screening of T2DM in asymptomatic subjects. ${ }^{17}$

\section{Parameters to assess outcome}

All patients enrolled in the study underwent a thorough clinical examination and a detailed history was taken, the patients were randomly allocated to 2 groups and were called for a follow-up at 3 and 6 months. The glycemic parameters (fasting blood glucose, postprandial blood glucose and glycosylated haemoglobin) were evaluated at baseline, 3 months and 6months, while lipid parameters (total cholesterol, serum triglycerides level, low-density lipoprotein-cholesterol (LDL-C), high-density lipoprotein-protein and very low density lipoprotein estimation) were estimated at 0 and 6 months. The serum creatinine, serum uric acid, Aspartate Aminotransferase (SGOT) as well as Alanine transaminase (SGPT) levels were also estimated at 0 and 6 months.

\section{Statistical analysis}

The results were prepared in excel sheet and was tabulated as Mean \pm SD (mean \pm standard deviation). Data analysis was done by using Graphpad software. Non-parametric data was analysed using Chi-Square Test and parametric data by using Student ' $t$ ' test. Statistically significance was considered as $\mathrm{p}<0.05$. 


\section{RESULTS}

A total of 254 patients suffering from T2DM were screened for present study, 30 patients not fulfilling inclusion criteria were excluded from the study, while 28 patients did not give written informed consent and hence were not included in study.

Total 196 patients were randomized through random number table into two groups (groups $\mathrm{G}$ and $\mathrm{S}$ ). Patients in Group $\mathrm{G}$ were given Glimepiride, and Group $\mathrm{S}$ were given Sitagliptin, along with metformin. A total of 161 patients completed study and hence were included in the analysis of the result, 35 patients did not turn up for the follow-up at 3 and 6 months (19 in Group G and 16 in Group S).

Group G had 82 patients, while 79 patients in Group S completed the 6-month duration of study and were analysed for result.

Patient's baseline parameters in two group are shown in Table 1, though the biochemical parameters were slightly higher in sitagliptin group, but it was not statistically significant. A total of 96 males were included in the study, 49 in Group $\mathrm{G}$ and 47 in group $\mathrm{S}$.

Table 1: Demographic comparison at baseline (Mean \pm SD).

\begin{tabular}{|lll|}
\hline Parameter & Group G $(\mathbf{n = 8 2})$, Glimepiride+Metformin & Group S (n=79), Sitagliptin+Metformin \\
\hline Age (years) & $56.1 \pm 12.5$ & $54.3 \pm 10.5$ \\
\hline Weight in Kg & $71.2 \pm 11.0$ & $70.8 \pm 9.8$ \\
\hline FBG (mg/dl) & $185.1 \pm 49.0$ & $189.2 \pm 32.4$ \\
\hline PPBG (mg/dl) & $276.0 \pm 63.6$ & $300.2 \pm 62.9$ \\
\hline Hb1 Ac (mmol/mol) & $9.0 \pm 1.4$ & $9.4 \pm 0.8$ \\
\hline TC $(\mathrm{mg} / \mathrm{dl})$ & $204.1 \pm 40.3$ & $210.4 \pm 39.3$ \\
\hline TG $(\mathrm{mg} / \mathrm{dl})$ & $167.9 \pm 58.4$ & $180.5 \pm 57.6$ \\
\hline LDL $(\mathrm{mg} / \mathrm{dl})$ & $124.1 \pm 33.7$ & $138.1 \pm 44.6$ \\
\hline VLDL (mg/dl) & $28.1 \pm 14.4$ & $31.4 \pm 12.9$ \\
\hline HDL $(\mathrm{mg} / \mathrm{dl})$ & $48.3 \pm 9.7$ & $48.9 \pm 12.9$ \\
\hline UA $(\mathrm{mg} / \mathrm{dl})$ & $4.3 \pm 1.1$ & $4.5 \pm 1.2$ \\
\hline SC $(\mathrm{mg} / \mathrm{dl})$ & $0.9 \pm 0.2$ & $0.9 \pm 0.2$ \\
\hline SGOT (IU/L) & $37.3 \pm 7.0$ & $39.6 \pm 6.9$ \\
\hline SGPT $(\mathrm{IU} / \mathrm{L})$ & $41.0 \pm 14.5$ & $44.4 \pm 9.2$ \\
\hline
\end{tabular}

\section{Fasting blood glucose levels}

A statistically $(\mathrm{p}<0.05)$ significant fall in fasting blood glucose in Group $G$ at 3 months $(185.07 \pm 49.04$ vs. $116.23 \pm 14.53)$ and 6 months $(185.07 \pm 49.04$ vs. 107.09 \pm 18.75$)$. Similarly, a statistically $\quad(\mathrm{p}<0.05)$ significant fall in fasting blood glucose in Group $\mathrm{S}$ at 3 months $(189.15 \pm 32.37$ vs. $128.40 \pm 19.89)$ and 6 months $(189.15 \pm 32.37$ vs. $103.66 \pm 11.27)$. There was a statistically $(\mathrm{p}<0.05)$ significant fall in fasting plasma glucose at 3 months in Group $\mathrm{G}$ as compared to Group S, both groups had comparable result at 6 months (Figure 1).

\section{Postprandial blood glucose levels}

A statistically $(\mathrm{p}<0.05)$ significant fall in post prandial blood glucose in Group $\mathrm{G}$ at 3 months $(275.95 \pm 63.6$ vs. $167.04 \pm 27.08)$ and 6 months $(275.95 \pm 63.60$ vs. 141.36 \pm 31.06$)$. Similarly, statistically significant difference $(\mathrm{p}<0.05)$ was found.

There is fall in postprandial blood glucose in Group $\mathrm{S}$ at 3 months $(300.17 \pm 62.88$ vs. $168.74 \pm 26.47)$ and 6 months
(300.17 \pm 62.88 vs. $134.21 \pm 14.11)$. both the groups had comparable result at 3 and 6 months (Figure 1).

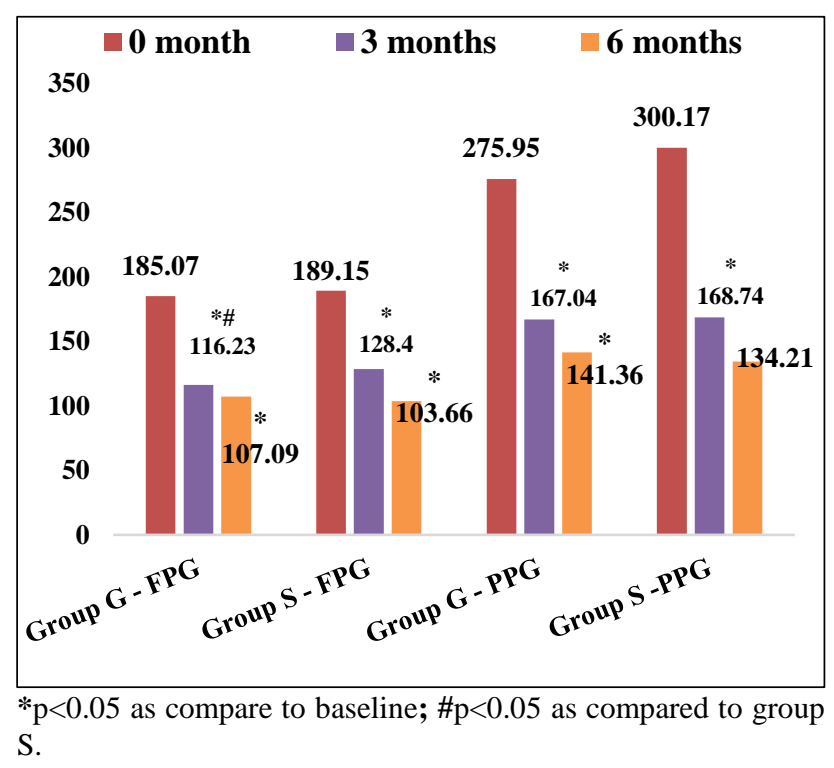

Figure 1: Blood glucose levels. 


\section{Glycosylated haemoglobin}

There was a statistically $(\mathrm{p}<0.05)$ significant fall in Hb1 Ac in Group $\mathrm{G}$ at 3 months $(8.99 \pm 1.36$ vs. $7.60 \pm 0.81)$ and 6 months $(8.99 \pm 1.36$ vs. $6.74 \pm 0.76)$. Similarly, there was a statistically $(\mathrm{p}<0.05)$ significant fall in Hb1 Ac in Group $\mathrm{S}$ at 3 months $(9.39 \pm 0.82$ vs. $8.26 \pm 0.78)$ and 6 months $(9.39 \pm 0.82$ vs. $6.84 \pm 0.36)$. There was a statistically $(\mathrm{p}<0.05)$ significant fall in $\mathrm{Hb} 1 \mathrm{Ac}$ at 3 months in Group G as compared to Group S, both groups had a comparable level of Hb1 Ac at 6 months (Figure 2).

\section{Biochemical parameters}

The biochemical parameters are shown in Table 2, both groups showed a statistically $(\mathrm{p}<0.05)$ significant progress in lipid profile, SGOT and SGPT level at 6 months as compared to baseline, and no significant difference between group.

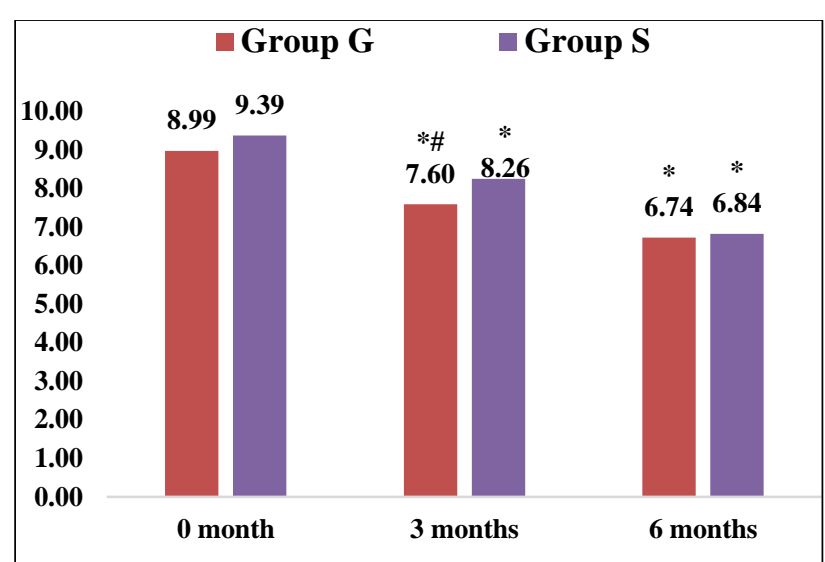

*p $<0.05$ as compare to baseline; \#p $<0.05$ as compared to group S.

Figure 2: Glycosylated haemoglobins levels in both groups.

Table 2: Biochemical parameters in both groups at baseline and 24 weeks (Mean \pm SD).

\begin{tabular}{|lllll|}
\hline \multirow{2}{*}{ Parameter } & \multicolumn{2}{l|}{$\begin{array}{l}\text { Group G (n=82), } \\
\text { Glimepiride+Metormin }\end{array}$} & \multicolumn{2}{l|}{$\begin{array}{l}\text { Group S (n=79), } \\
\text { Sitagliptin+Metformin }\end{array}$} \\
& 0 month & $\mathbf{6 ~ m o n t h s}$ & $\mathbf{0 ~ m o n t h}$ & 6 months \\
\hline TC (Total cholesterol) $(\mathrm{mg} / \mathrm{dl})$ & $204.1 \pm 40.3$ & $148.5 \pm 30.7^{*}$ & $210.4 \pm 39.3$ & $146.1 \pm 27.8^{*}$ \\
\hline TG (Serum triglycerídes) $(\mathrm{mg} / \mathrm{dl})$ & $167.9 \pm 58.4$ & $121.2 \pm 29.8^{*}$ & $180.5 \pm 57.6$ & $119.0 \pm 29.6^{*}$ \\
\hline LDL (Low densíty lipoprotein) $(\mathrm{mg} / \mathrm{dl})$ & $124.1 \pm 33.7$ & $81.0 \pm 29.4^{*}$ & $138.1 \pm 44.6$ & $74.3 \pm 21.1^{*}$ \\
\hline VLDL (Very low density lipoproteíns) $(\mathrm{mg} / \mathrm{dl})$ & $28.1 \pm 14.4$ & $17.7 \pm 5.7^{*}$ & $31.4 \pm 12.9$ & $19.9 \pm 10.2^{*}$ \\
\hline HDL (Hígh density lipoproteín) (mg/dl) & $48.3 \pm 9.7$ & $49.6 \pm 13.0$ & $48.9 \pm 12.9$ & $50.3 \pm 12.4$ \\
\hline UA (Serum uric acid) (mg/dl) & $4.3 \pm 1.1$ & $4.1 \pm 0.9$ & $4.5 \pm 1.2$ & $4.3 \pm 1.0$ \\
\hline SC (SerumCreatiníne) (mg/dl) & $0.9 \pm 0.2$ & $0.8 \pm 0.2$ & $0.9 \pm 0.2$ & $0.9 \pm 0.2$ \\
\hline SGOT (Aspartate aminotransferase) (IU/L) & $37.3 \pm 7.0$ & $34.9 \pm 7.0^{*}$ & $39.6 \pm 6.9$ & $36.5 \pm 5.7^{*}$ \\
\hline SGPT (Alanine transaminase) (IU/L) & $41.0 \pm 14.5$ & $35.4 \pm 7.7^{*}$ & $44.4 \pm 9.2$ & $38.5 \pm 6.4^{*}$ \\
\hline
\end{tabular}

\section{DISCUSSION}

The result of this study shows that both glimepiride and sitagliptin with metformin lowered both the fasting blood glucose as well as postprandial blood glucose at 3 and 6 months. The lowering of plasma glucose in both the groups was statistically significant, though glimepiride was found to have better effect in lowering the plasma glucose at 3 months, but both the drugs were comparable at 6 months. This study also showed that glycosylated haemoglobin was lowered in both groups at 3 and 6 months as compared to baseline, with glimepiride having better control of glycosylated haemoglobin at 3 months. Though at the end of the study period both drugs were comparable. The results of this study also demonstrated that the biochemical parameters were better controlled at 24 weeks in both the groups. The result of this study is consistent with findings of the previous studies, which also showed that sitagliptin was equally effective as glimepiride though this study also showed a better control of other biochemical parameter like lipid profile better controlled at 24 weeks in both groups. ${ }^{14,18,19}$

A study done by Srivastava $S$ et al, also demonstrated that both the drugs were equally effective though it differed from this study as it demonstrated that patients on glimepiride had better glycemic control and patients on sitagliptin had better safety profile on addition to metformin monotherapy. ${ }^{20}$

The study also showed that target HbA1c was achieved in higher number of patients on glimepiride as compared to sitagliptin (36\% vs. $12 \%$ ) and higher number of patients reported of weight gain and incidence of hypoglycaemia (4\% vs $8 \%$ ) with glimepiride. These results are very much similar to this study as in this study also there was a significant reduction in HbA1C (glycosylated haemoglobin) in patients on glimepiride at 3 months. Though this study differed from the study as this study showed comparable glycemic control at 6 months. ${ }^{20}$ 
One more study by Muthukrishnan J et al, slightly differed in its finding as it showed that sitagliptin faring better than glimepiride in newly diagnosed patients of diabetes mellitus in both effectiveness and safety. Sitagliptin group also had less weight gain and chances of hyperglycaemia. ${ }^{21}$

Another study done by Kumar S et al, to evaluate the effects of add-on Sitagliptin/ Glimepiride on efficacy, safety and treatment satisfaction which was retrospective in nature, demonstrated levels of glycosylated hemoglobin after 3-6 months of therapy was not significant. ${ }^{22}$ Though patients on glimepiride had lower levels of fasting blood glucose and postprandial blood glucose, with sitagliptin having better overall treatment satisfaction score. This study is quite similar to this as in this study also there was a significant better glycemic control in this study at 3 and 6 months, but this was evident in both glimepiride as well as sitagliptin group. ${ }^{22}$

One more study by Anjoom $\mathrm{M}$ et al, comparing glimepiride and sitagliptin with metformin demonstrated significant improvement in both groups on various glycemic parameters at the end of study. ${ }^{23}$ Results of this study were same as in this study. Apart from this we also found improvement in glycemic parameters at 3 months and 6 months in comparison to baseline which was statistically significant. Though Glimepiride group was much better at 3 months and both the groups were comparable at 6 months. ${ }^{23}$

This study has few limitations, first is the small sample size as a larger sample size could have different results, but due to paucity of time, it could not be done. Secondly the duration of follow-up in this study is limited to 24 weeks; the results could have varied in a longer follow-up, as there is decreased awareness in patients so a long follow up study could not be planned as a large number of patients tend to drop out from study. The results could have varied if the study would have been double-blind, this could not be done due to constrains oaf resources.

\section{CONCLUSION}

This study concludes the comparison of metabolic effects of metformin with Glimepiride (group G) and metformin with Sitagliptin (group S) in T2DM patients and it was found that none group was superior. Both groups showed significant reduction of FPG, PPBG, HbA1C, TC, TAG, LDL, VLDL at 3 months and 6 months from baseline value. However, the results were better in group $G$ (metformin+Glimepiride) at 3 months but at 6-month group $\mathrm{S}$ (metformin+Sitagliptin) was better. But in group $\mathrm{S}$ (metformin+Sitagliptin) rise in HDL was more. So, both the drug combinations were tolerable, safe with similar efficacy.

\section{Funding: No funding sources}

Conflict of interest: None declared

Ethical approval: The study was approved by the Institutional Ethics Committee

\section{REFERENCES}

1. Inzucchi SE, Bergenstal RM, Buse JB, Diamant M, Ferrannini E, Nauck M, et al. Management of hyperglycemia in type 2 diabetes: a patient-centered approach: position statement of the American Diabetes Association (ADA) and the European Association for the Study of Diabetes (EASD). Diabetes Care. 2012;35(6):1364-79.

2. Turner RC, Cull CA, Frighi V, Holman RR. Glycaemic control with diet, sulfonylurea, metformin, or insulin in patients with type 2 diabetes mellitusprogressive requirement for multiple therapies (UKPDS 49). JAMA. 1999;281(21):2005-12.

3. Acharya KG, Shah KN, Solanki ND, Rana DA. Evaluation of antidiabetic prescriptions, cost and adherence to treatment guidelines: A prospective, cross-sectional study at a tertiary care teaching hospital. J Basic Clin Pharm. 2013;4(4):82-7.

4. Lim PC, Chong CP. What's next after metformin? Focus on sulphonylurea: Add-on or combination therapy. Pharm Pract (Granada). 2015;13(3):606.

5. Nandy M, Mandal A, Banerjee S, Ray K. A prescription survey in diabetes assessing metformin use in a tertiary care hospital in Eastern India. J Pharmacol Pharmacotherapeut. 2012;3(3):273-5.

6. Kalra S, Aamir AH, Raza A, Das AK, Azad Khan AK, Shrestha D, et al. Place of sulfonylureas in the management of type 2 diabetes mellitus in South Asia: A consensus statement. Indian $\mathrm{J}$ Endocrinol Metab. 2015;19(5):577-96.

7. Basit A, Riaz M, Fawwad A. Glimepiride: Evidencebased facts, trends, and observations (GIFTS). Vasc Health Risk Manag. 2012;8:463-72.

8. Moon JS, Ha KS, Yoon JS, Lee HW, Lee HC, Won $\mathrm{KC}$, et al. The effect of glargine versus glimepiride on pancreatic $\beta$-cell function in patients with type 2 diabetes uncontrolled on metformin monotherapy: Open-label, randomized, controlled study. Acta Diabetol. 2014;51(2):277-85.

9. Singh P, Khan FA, Hemnani TJ, Matreja PS, Singh VK. A prospective study to analyze the metabolic effects of Metformin with Glimepiride on type 2 Diabetic patients of North India. Ann Int Med Den. Res. 2016;2(4):242-5.

10. Singh P, Singh VK, Hemnani TJ, Matreja PS. A Prospective study on effectiveness of Sitagliptin with Metformin in Type 2 Diabetic patients in a Tertiary Care Hospital. Int J Med Res Prof.2016;2(3):246-8.

11. Gerrald KR, Van Scoyoc E, Wines RC, et al. Saxagliptin and sitagliptin in adult patients with type 2 diabetes: A systematic review and meta-analysis. Diabetes Obes Metab. 2012;14(6):1481-92.

12. Dicker D. DPP-4 inhibitors: Impact on glycemic control and cardiovascular risk factors. Diabetes Care. 2011;34(Suppl 2):S276-8.

13. Karagiannis T, Paschos P, Paletas K, et al. Dipeptidyl peptidase-4 inhibitors for treatment of type 2 diabetes mellitus in the clinical setting: Systematic review and meta-analysis. BMJ. 2012;344:e1369. 
14. Nauck MA, Meininger G, Sheng D, Terranella L, Stein PP. Efficacy and safety of the dipeptidyl peptidase-4 inhibitor, sitagliptin, compared with the sulfonylurea, glipizide, in patients with type 2 diabetes inadequately controlled onmetformin alone: a randomized, double-blind, non-inferiority trial. Diabetes Obes Metab. 2007;9(2):194-205.

15. Shimoda S, Iwashita S, Sekigami T, Furukawa N, Matsuo Y, Ichimori S, et al. Comparison of the efficacy of sitagliptin and glimepiride dose-up in Japanese patients with type 2 diabetes poorly controlled by sitagliptin and glimepiride in combination. J Diabetes Invest. 2014;5(3):320-6.

16. Hou L, Zhao T, Liu Y, Zhang Y. Efficacy and safety of sitagliptin compared with sulfonylurea therapy in patients with type 2 diabetes showing inadequately controlled glycosylated haemoglobin with metformin monotherapy: A meta-analysis. Experiment Therapeut Med. 2015;9(4):1528-36.

17. American diabetes Asoociation. Diagnosis and Classification of Diabetes Mellitus. Diabetic care 2014;37(Suppl 1):S81-90.

18. Arechavaleta R, Seck T, Chen Y, Krobot KJ, O’Neill EA, Duran L, et al. Efficacy and safety of treatment with sitagliptin or glimepiride in patients with type 2 diabetes inadequately controlled on metformin monotherapy: a randomized, double-blind, noninferiority trial. Diabetes Obes Metab. 2011;13(2):160-8.

19. Arjona Ferreira JC, Marre M, Barzilai N, Guo H, Golm GT, Sisk CM, et al. Efficacy and safety of sitagliptin versus glipizide in patients with type 2 diabetes and moderate-to-severe chronic renal insufficiency. Diabetes Care. 2013;36:1067-73.

20. Srivastava S, Saxena GN, Keshwani P, Gupta R. Comparing the efficacy and safety profile of sitagliptin versus glimepiride in patients of type 2 diabetes mellitus inadequately controlled with metformin alone. J Assoc Physicians India. 2012;60(2):27-30

21. Muthukrishnan J, Dawra S, Marwaha V, Bishnoi JS, Narayanan CS. Diabetes mellitus in the young: Gliptins or sulfonylurea after metformin? Indian J Endocrinol Metabol. 2012;16(Suppl 2):S474-6.

22. Kumar S, Pathak AK, Saikia D, Kumar A. Efficacy, safety and treatment satisfaction of glimepiride vs. Sitagliptin in combination with metformin in type 2 diabetes mellitus. J Clin Diagn Res. 2015;9(12):FC0710.

23. Anjoom M, Dutta S, Meg MA, Verma A, Bawa S, Kant R. Comparative evaluation of combination of metformin and Glimepiride with that of metformin and Sitagliptin in type 2 diabetes mellitus with respect to glycaemic target. Int $\mathbf{J}$ Med Sci Public Health. 2015;4(4):476-80.

Cite this article as: Singh $\mathrm{P}$, Choudhary $\mathrm{R}$, Singh VK, Matreja PS. Comparison of metabolic effects of glimepride and sitagliptin with metformin in patients suffering from type 2 diabetes mellitus in a tertiary care hospital. Int J Basic Clin Pharmacol 2019;8:1467-72. 